SHS Web of Conferences 14, 01012 (2015)

DOI: $10.1051 /$ shsconf/20151401012

(c) Owned by the authors, published by EDP Sciences, 2015

\title{
Practice of PBL in the Reading Teaching Strategies
}

\author{
Yingting Wang ${ }^{1}$, Jian Wang ${ }^{2,3}$ and Hao Sheng ${ }^{4, a}$ \\ ${ }^{1}$ Nanjing Yuying Foreign Language School, 210003 Nanjing Jiangsu, China \\ ${ }^{2}$ Cyber Physical System R\&D Center, The Third Research Institute of Ministry of Public Security, 201204 Shanghai, China \\ ${ }^{3}$ School of Electronic Information and Electrical Engineering, Shanghai Jiao Tong University, 200240 Shanghai, China \\ ${ }^{4}$ School of Computer Science and Engineering, Beihang University, 100191 Beijing, China
}

\begin{abstract}
Combined PBL with some advanced foreign reading teaching strategies, we choose the most suitable way to give lessons and bring up students ability to think of questions. Based on teaching experience for several years, we propose some teaching strategies in English reading teaching to help students improve the efficiency and accuracy of reading with the help of PBL. After practice, students' innovation and cooperation are strengthened and the width and depth of their questions are improved.
\end{abstract}

Keywords. PBL; problem-based learning; reading teaching strategies

\section{Introduction}

In the new round of the curriculum reform, new requirements of the reading teaching are put forward to teachers. English Curriculum Standard emphasizes that 'English curriculum should pay attention to the students' interest of learning, life experience and cognitive level and it should also advocate practice, participation, cooperation, the exchange of learning methods and task-based teaching way'. In junior high school, the introduction of PBL in English reading teaching seems to be injected with fresh blood. However, for teaching practice, not only teachers but also students often have many problems, e.g. simplex question design, lack of internal links, severe randomness etc. These problems often do harm to improve students' abilities to understand, imagine and create.

Up till now, many teachers in most western countries prefer to use questions to lead their lessons or courses. They believe this method will maximize the exploring ability of students. However, many English teachers in China still prefer to use some old traditional methods to teach our students, which let teachers explain everything to students without some questions. In this case, the learning ability of our students can't be improved. So we advocate putting PBL into our English teaching.

PBL means 'problem-based learning' which was invented by Barrows, who was a professor of neurology in

\footnotetext{
${ }^{a}$ Corresponding author: shenghao@buaa.edu.cn

${ }^{1}$ Yingting Wang: 396131248@qq.com

2 Jian Wang: wjconan@ieee.org
}

McMaster University ${ }^{[1]}$. As the core of PBL, "Question" is the main way for students to participate in class teaching of reading, to get information, to consolidate skills and to communicate with each other. For meeting the requirements of effective class teaching in modern English reading teaching system, teachers should master the methods and skills of question design on reading materials, or guide students to raise questions by themselves. Good design of questions will greatly improve the effectiveness of reading teaching, and promote the development of students' reading ability, as well as their innovation their creativity at the same time. These essentials will lay a solid foundation for independent learning and future research. Combined with PBL, this paper presents a new approach to improve reading efficiency and accuracy, and discuss some keypoints by analyzing several practical cases

\section{Practice of $\mathrm{PBL}$}

\subsection{Pay attention to influence of preview ques- tions and evaluation questions within reading teaching strategies}

At present, some domestic experts and scholars are putting 'questions' into the reading teaching, which are divided into preparation questions, memory questions, comprehension questions, analysis questions and evaluation questions. In our traditional reading teaching, memory questions, comprehension questions and analysis questions are paid more attention yet. For example, most of teachers are used to asking questions to remind the students what they learnt in previous class, in order to 
help the students be familiar with the contents in current class as soon as possible. On the other hand, some teachers directly put forward several comprehension problems after analyzing the entire passage.

\subsubsection{Preview questions}

However, in reading teaching, the preparation of preview questions plays an important role in the implementation of PBL, which constructs high-quality question scenarios for the whole class. Specifically, before learning the new article, the students are required to literature on given topics or keywords, to grasp the background knowledge and inspire their imagination and prediction. Meanwhile, the students are also asked to prepare 1 to 4 questions with available answers about the topics. The efficiency of reading will naturally be raised by $20 \%$ if the students bring these questions into the class. Fighting a "ready battle" rather than learn the class blindly, the students have already entered an energetic when they enter the classroom.

\subsubsection{Brainstorming}

Similar effect can be achieved by brainstorming before the class, which can have a brief check the students' knowledge fund. The preview question and brainstorming are both solid foundations for the forthcoming reading phases. In reading strategies, it is important to predict what the material will tell them. When doing reading exercises, many students prefer to read articles and titles blindly and to treat them separately without prediction of reading materials based on their existing knowledge fund. If the teachers prepare some questions or the students themselves bring up some questions related to the topics of reading materials, it can be possible to improve the efficiency of reading and arouse students' interest significantly.

\subsubsection{Background information and knowledge}

The essence of PBL is to use questions through the whole teaching process to achieve the goal of teaching, to cultivate the students' thinking ability, to stimulate their innovation potential. The modern construction theory believes that learning is a process of active construction learning based on knowledge and experience, rather than an individual passive process. Learning also need actively construct the new cognitive schema and complete the new cognitive structure step by step. In this process, the students can not only achieve the active construction of knowledge, but also greatly enrich their thinking process after various conflict and harmony between new and old knowledge, or theory and practice. Thus, within the reading teaching, teachers should let the students have a certain 'knowledge and experience', which is the importance of preview questions. Under this premise, the intelligence of the students can be developed to the utmost extent. Otherwise, it is unrealistic for the teachers to dig out as many meaningful questions as possible from the students within 45 minutes. In this case, teachers should identify the entry point when designing 1 or 2 preview questions, which can cause a better understanding of the entire article, opening minds, and activated thoughts.

\subsubsection{Evaluation questions}

Furthermore, the proposition and solution of the evaluation questions are also considered as an important process of the sublimation of PBL. They encourage students to comment questions and then demonstrate the reasons. Teachers who have rich teaching experience can provide a proper evaluation and a timely handling on students' answers. When evaluating students' answers, the teachers must tell where the students answer correctly or incorrectly, or where is not correct enough, and then give the reason. If so, it can make the students to obtain distinct judgement, clear boundary and effective thinking training. It is evidently harmful of providing the vague evaluation or even without any evaluation. Unfortunately, many young teachers often ignore this point in practice.

\subsection{Encourage teachers and students to think of various forms of questions and expand both width and breadth of questions}

In addition, the practice of PBL in the reading teaching strategies mainly reflects in the class, which means to use PBL and the reading teaching strategies together to improve efficiency of the learners and accuracy of reading comprehension.

\subsubsection{Try to design different forms of questions}

At present, many teachers who are constantly aware of the important role of questions in reading teaching have begun to actively explore, practice new teaching ideas and methods. For example, they begin to realize whether the question designs on reading teaching are too simple to answer them through deliberate thinking. These simple questions remain the students' thoughts at a low level, and it is not good for the development of students' divergent thinking. Therefore, the teachers will gradually begin to design questions based on students' existing logical level, and they also pay attention to creating the proper information ditch for cultivating interest and developing their intelligence. Many teachers or the students themselves can increase the depth and difficulty of the questions according to the topic or the contents of the reading materials. Even some teachers have been trying to put forward some divergent thinking questions in order to improve the students' abilities of analysis and reasoning. Anyway, from the horizontal perspective, the questions we designed are still low and simplex at times.

As teaching $<$ Festival---Halloween $>$, a teacher designed the questions as follows:

- How do we celebrate Mid-Autumn Festival? What about Americans?

- Do you get anything on Mid-Autumn Festival?

- How do the children get some candies?

- If you want people not to know who you are, what can you do? 
- Do you want a pumpkin lantern? How can you make it?

- Why don't Wendy and her family have cold drinks at the party?

We found that the teacher had considered the natural curiosity of students when designing the questions. Compare with the traditional questions which many teachers may form below, this teacher succeeded in arousing the students' interest. (The following are traditional questions that our teachers often design)

- What do Americans do to celebrate Halloween?

- What do the children do for Halloween?

- Why do the children dress up at Halloween?

- How do they make a pumpkin lantern?

- When do they have a party to celebrate Halloween?

Obviously, compared with the two kinds of previous questions, these 5 questions are so direct and simple that students can almost answer them without thinking.

But now, we began to deeply explore why we always designed questions so mechanically in the practice of PBL? Although some teachers have begun to gradually stimulate students' thinking in some cases, the questions which they designed are still out of date. In the use of reading teaching strategies, the teachers only pay attention to the questions design on skimming and scanning. After some years' teaching, actually English teachers have more strategies besides the two old ones above. We propose that PBL can be used to have more innovation in forms of questions, which let the students not be afraid of various questions. The interest of students can be aroused, and even the students themselves can scheme out different question forms. In this case, the teachers are put forward higher requirements. Therefore, with the same topic, we made the following changes in the design of questions:

- Reading activity:

I. Read the following passage about Halloween, then complete the following outline by adding information to each of the points listed in it;Celebrations of Halloween

a) Examples of celebrations of Halloween
1) wear masks and costumes
2) have delicious food and drinks
3) play trick or treat

b) Compare celebrations of Halloween and Midautumn festival

Table 1. The contrast between two festivals.

\begin{tabular}{lll}
\hline & Halloween & Mid-autumn festival \\
\hline 1 & wear masks and costumes & visit relatives \\
2 & have delicious food and drinks & eat mooncakes \\
3 & play trick or treat & watch the moon \\
\hline
\end{tabular}

II. The preparations of each celebration

1) buy or make some masks and costumes

2) prepare some food and drinks

3) buy some pumpkins and candies

Except the forms of questions above, we can also use the following advanced methods to design reading questions:

\section{a) Outlining}

Outlining is a very important strategy in our reading teaching. In Chinese teaching, when we want to analyze a
Chinese article, the first thing is not to answer questions but to divide the whole article into several parts or list an outline. As well known, it's better to grasp the structure and the general ideas of the reading materials. Why can't we introduce this policy to the English reading teaching? With the same purpose but different designs, the students will feel fresher and be more willing to answer the questions. With the diversification of design, students also become more interested in various kinds of questions when reading. Meanwhile, the width and depth of thinking has been expanded greatly.

What do Americans do to celebrate Halloween?

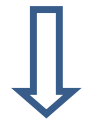

How do we celebrate Mid-Autumn Festival?

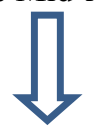

I. Celebrations of Halloween

a) Examples of celebrations of Halloween

1) wear masks and costumes

2) have delicious food and drinks

3) play trick or treat

b) Compare celebrations of Halloween and Midautumn Festival

Table 2. The contrast between two festivals.

\begin{tabular}{lll}
\hline Halloween & Mid-autumn festival \\
\hline 1 & wear masks and costumes & visit relatives \\
2 & have delicious food and drinks & eat mooncakes \\
3 & play trick or treat & watch the moon \\
\hline
\end{tabular}

We attempted to open up students' minds by using such a chart or an outline. With such an attempt, the students started to realize that questions can be designed like this. They use this chart or outline as a model and develop more ones, update the design of questions immediately. If this process continues, PBL is not just a boring method in the students' mind, it will be regarded as a learning method that the students are willing to try, to use, and to innovate.

\section{b) Scrambled stories}

In addition to the practice of PBL, we found that the students showed great interest in two strategies- scrambled stories and information transfer. Scrambled stories is also called the 'jigsaw reading', whose specific approach is to let the students rearrange the orders of some paragraphs according to their understanding on the article. This exercise is often seen in the national college entrance examination, we have a try on the junior high school students. Two similar paragraphs are put together, then let the students compare them and choose the most suitable paragraph in correct order. So that the students could try to become author of the reading material and could understand the thoughts of author by this way. This strategy not only examines the logic thinking of students, but also the reading comprehension.

\section{c) Information transfer}

Information transfer means changing text information into the pictures, routes or drawings according to the need. 
These images can help students understand the reading materials better. For example, we taught a reading text in the high school <dying to be thin>, which was too hard and complex for our junior high school students. When designing the activities, the strategy of information transfer is considered.

The first design is to make the students work in groups, cooperating to draw a simple picture according to their understanding of the reading material. It is observed that which group's comprehension is close to the original idea of author of the reading material, and painting of which group is the most creative. However, this activity would cost too much time, so we chose the combination strategy of scrambled stories and information transfer instead. We decided to disrupt the prepared drawings, disorder each paragraph, and then let the students match each instruction with the pictures. The pictures were in the correct orders, but the instructions weren't (as Fig. 1) with the same reading strategy but different designs of questions, which are quite new to them, the students responded particularly and positively. They were willing to answer such fresh kinds of questions. Meanwhile, the students had high enthusiasm, and their efficiency of reading was also greatly improved.
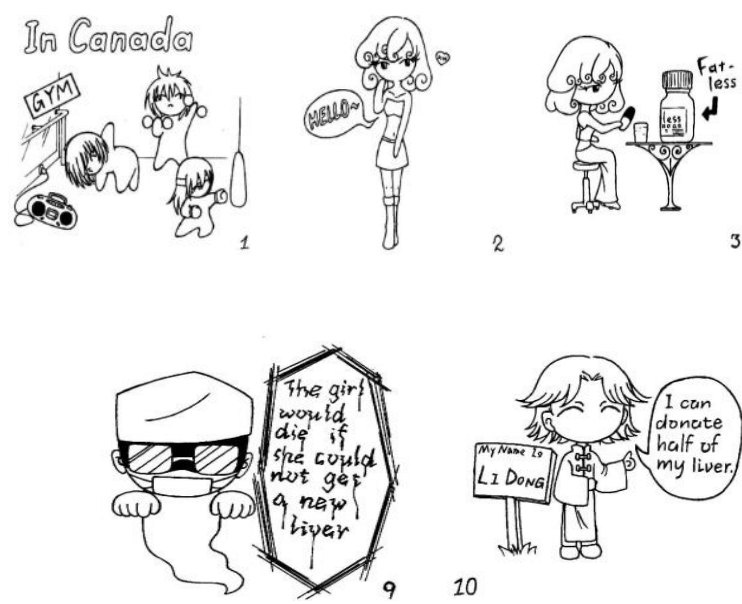

Figure 1. The drawing of the article dying to be thin.

In short, in the design of questions in the English reading teaching, it is very important for teachers to research on the types of questions, which requires teachers to do more practice on 'effects'. Generally speaking, the teachers (a) can use various ways of questions, such as Stone Fluxes Type, Selection and Comparison Type, Tracking Filled Factor Type etc. (b) should pay attention to the time of asking questions, the objects of questions, the way of asking questions and the evaluation of asking and answering questions.

\subsubsection{Expand the width and depth of questions}

We once gave such kind of design while teaching a reading material. The students are encouraged to work in group to analyze characters.

[1] Try to analyze these two monsters' personality from the following sentences:
Table 3. The contrast between two monsters.

\begin{tabular}{|c|c|}
\hline & Flossie's personality \\
\hline 1 & $\begin{array}{l}\text { I never seem to have any } \\
\text { luck at all.P4 }\end{array}$ \\
\hline 2 & $\begin{array}{l}\text { I belong to the same } \\
\text { family as Nessie.... But } \\
\text { we do have our differences } \\
\text { P5 }\end{array}$ \\
\hline 3 & $\begin{array}{l}\text { I'm a bit on the small side, } \\
\text { scared of the dark. I am } \\
\text { not all that keen on water. } \\
\text { P6 }\end{array}$ \\
\hline 4 & I felt dizzy and sick. P8 \\
\hline
\end{tabular}

5 I want to be spotted and noticed. But no matter what I do, nobody notices me at all. P12

6 Nessie doesn't care if she has a friend, but I do. I want someone who cares for me. I want someone who can see the real me. P14

7 But I didn't give up, I was determined to find a friend.P16

\author{
Nessie's personality \\ She swims down to the \\ dark depths of the loch. \\ P6 \\ She swims swift and \\ sure. P7 \\ If someone spots \\ Nessie, \\ she changes. P10 \\ She's famous. \\ She's a celebrity. P11
}

She only talks to me when she feels like it. P13

She doesn't care if she has a friend. P14

\section{A friend is someone who is like you, \\ but no one is like us, so we can't \\ have friends. P15 \\ I love scaring people! P16}

i. F: Lack of confidence. N: Bully.

ii. F: Not strong enough; Have her own defect. $\mathrm{N}$ : Have strong abilities.

iii. F: Want to be famous very much. $\mathrm{N}$ : Not care about being famous; but know clearly how to protect herself.

iv. F: Care more about others' feelings. $\mathrm{N}$ : Self-centered.

v. F: Have strong will to make true friends and never give up easily.

$\mathrm{N}$ : Too confident, but can see the situation clearly.

[2] Can you conclude the changes to Flossie from these pics?

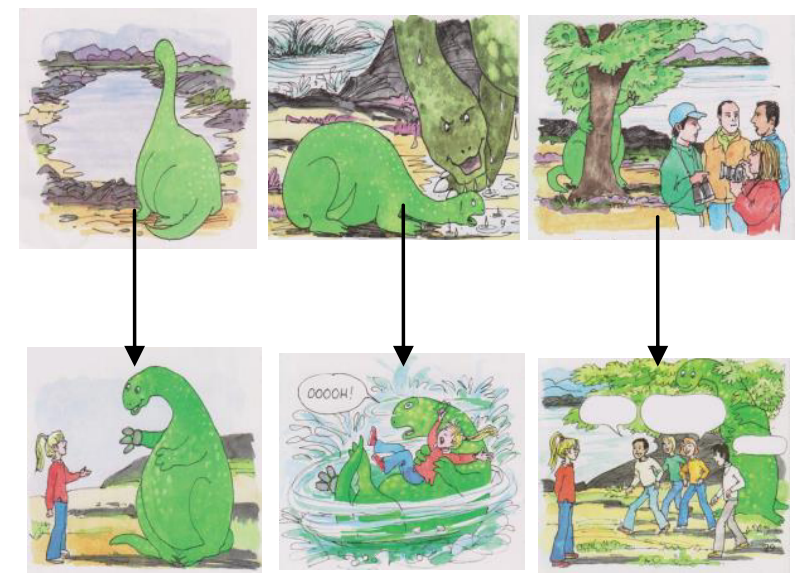

Figure 2.The changes to Flossie. 
i. Lonely $\longrightarrow$ Make new friends.

ii. Titch! Scared cat! Cry baby! $\longrightarrow$ Timid Brave

iii. Try to be spotted and noticed. $\longrightarrow$ Be around with her best friend

[3] And what makes Flossie have such kind of changes?

[4] Plot analysis: try to write down the general ideas of each chapter

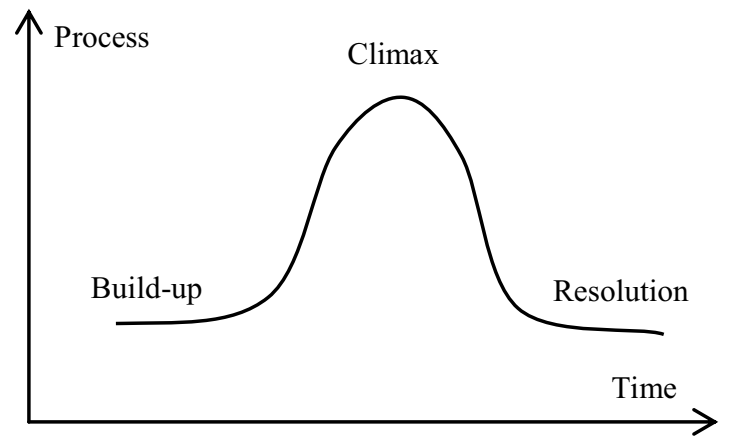

Figure 3. The development of the story.

Chapter 1The introduction of the monster---Flossie.

Chapter 2 No one cares about him.

Chapter 3 How does he find a friend?

Chapter 4He always stays with his friend

[5] Further discussion

i. What kind of people are strong inside?

ii. What are the real friends? What did real friends do to each other?

iii. What else can you learn from the book?

From these designs of questions, the students can understand and analyze the reading material more deeply and widely. Meanwhile, they can better grasp this article.

\section{Other matters needed attention}

In order to improve the efficiency of reading, teachers should pay more attention to the following aspects when using PBL in the practice of teaching strategies.

\subsection{More thinking time for the students before answering.}

As for teaching reading, many domestic teachers often try their best to lead the students by situations, pictures, questions etc. Undoubtedly, the leading methods have been proved to be effective in practice, and seem to be in accordance with student's cognitive development in junior high school. Nevertheless, for dozens of years, the students really can improve reading abilities due to these gorgeous leading processes? It is unrealistic that those students without any preparation generate infinite interest about the reading materials just through a few minute's leading process.

In fact, when the students understand what topic the teacher prepare to discuss and began to have their own thoughts on the topic, teachers have already shifted to next teaching topic. For the students, there is no enough time to digest the relevant information. Therefore, the importance of questions previewing is obvious. Don't be afraid to tell students the keywords or titles of reading materials, as each article may have different views, meanwhile, everyone may also have different ideas and thoughts on a same title. The students will have deeper impression after the sparks by the collision between their own ideas and the author's.

The process of answering questions is the results of the students' thinking. After previewing reading, students find questions or problems, and then teachers classify these questions. Subsequently, we can conclude that the students have had their first deep thinking. At this time, teachers need to encourage and inspire students, to give a scientific, reasonable, timely, and appropriate assessment to students. Moreover, teachers should also learn to leave enough blank time for students, which is very important for the students to use their brains and digest the knowledge.

\subsection{Innovation and cooperation need to be strengthened}

Teachers should make every attempt to guide the students to design and solve questions from all aspects, which questions are considered as the motivation of learning and the main line in the learning process. The learning process can be split into four stages, i.e. questiondiscovering, question-asking, question-analyzing and question-solving. Students' innovative consciousness and their reading and thinking abilities will be developed.

Many teachers think that reading is an individual behavior, so they always hesitate to let the students discuss in groups or do cooperative research. For some difficult questions, the teachers should guide the students to discuss in groups, lead them to think together and explore the ways and methods of solving questions. In this way, it can enlarge the top students' interest in exploring the deeper and further knowledge. At the same time, it can also help the weak students see their gap clearly, so they can set up confidence to learn from the top students and get inspiration from group study. Furthermore, it enhances the students' cooperative consciousness and cultivates the spirit of collaboration. This stage is the deep process of the whole class teaching, which makes thinking active between teachers and students or among students. The stage also expands the teaching contents and thinking space. Not only teachers but also students are all in the state of positive thinking and active learning, when they ask or answer questions or meditate or discuss something. Although each of the students may experience the difficulty of learning, they can improve their knowledge and harvest a lot of joy.

\section{Conclusions}

In conclusion, both teachers and students should often make ourselves be in the state of 'thinking' and combine 'learning', 'suspecting' and 'thinking' together. We need to strengthen the awareness of questions, expand the 
dimension of producing questions and form the habit of thinking. We also need to continue to use all kinds of practical skills and strategies in the process of reading teaching. In all, we believe that the students who use PBL will be successful in making great progress in reading.

\section{Acknowledgement}

This paper was sponsored by following projects:

- National High-tech R\&D Program of China ("863 Program") (No. 2013AA01A603);

- Program of Science and Technology Commission of Shanghai Municipality (No. 12510701900);

- 2012 IoT Program of Ministry of Industry and Information Technology of China.

\section{References}

1. Problem-Based Learning at Queen's University [OL]. http://meds.queensu.ca/medicine/pbl/pblnews.htm
2. What is Problem-Based Learning? http://www.udel.edu/pbl/cte/jan95-what.html, 199702-20.

3. What is Problem-Based Learning? http://www.udel.edu/pbl/dancase3.html, 1997-07-12.

4. D. M. Kaufman. Problem-based learning-time to step back? [J]. Medical Education, 2000, (34):509-511.

5. Barrows HS. Ataxcnomy of Problem-based learning methods [J]. Medical Education, 1986, (20):481-486.

6. M. McParland, L. M. Noble \& G. Livingston. The effectiveness of problem-based learning compared to traditional teaching in undergraduate psychiatry $[\mathrm{J}]$. Medical Education, 2004, 38(8):859-867.

7. Donald R. Woods. Problem-based learning: How to gain the ost from PBL. First ed. Pbl Waterdown, Ontario, 1994.

8. H. S. Barrows. A taxonomy of problem-based learning methods[J]. Medical Education, 1985, 20:481486. 